\title{
Diurnal Variation in the Frequency of Heavy Precipitation in Japan
}

\author{
By Fumiaki Fujibe \\ Meteorological Research Institute, Tsukuba, Japan \\ (Manuscript received 2 March 1999, in revised form 12 August 1999)
}

\begin{abstract}
By using data for 18 years, diurnal variation in the frequency of heavy precipitation in Japan was analyzed. Diurnal variation patterns at each station were obtained for three durations (one, three and six hours), and several thresholds ranging from moderate to very high intensities $(5-80 \mathrm{~mm} / \mathrm{h}, 10-160 \mathrm{~mm} / 3 \mathrm{~h}$ and $20-320 \mathrm{~mm} / 6 \mathrm{~h}$ ). Then their regional characteristics were examined by using the fuzzy $c$-means method (FCM) in a search for representative patterns. The results are summarized as follows: (a) In coastal regions a morning maximum prevails, especially on the western side of land, (b) A broad maximum around midnight is found in many regions, especially on the southern and eastern sides of mountainous regions, as well as a part of the inland region, (c) A sharp maximum in late afternoon is found in part of the inland regions, especially in the eastern part of mountain regions and the adjacent plain, and (d) A maximum around midday is found over the Nansei Islands. The midnight maximum is more conspicuous for heavier precipitation on longer time scales (three- and six-hourly), in agreement with the empirical knowledge among forecasters that disastrous rainfall is more often encountered in the nighttime.
\end{abstract}

\section{Introduction}

The main features of diurnal precipitation variation in Japan (Fig. 1) has already been documented. Fujibe (1988) showed that localized precipitation had a distinct afternoon maximum in inland regions, and a nocturnal or morning maximum over coastal regions, while widespread precipitation had a weak morning maximum over the whole country, except for the prevalence of midday maxima over the Nansei Islands. Similar results were obtained by Tagami (1990), and Oki and Musiake (1994), with somewhat different approaches and also by Misumi (1999) on the basis of radar echo statistics. Recently Kuwagata (1997) and Saitoh and Kimura (1998) analyzed diurnal and regional features of convective rainfalls in the Central Mountain region, with emphasis on the effects of thermally driven circulations.

Diurnal variation of heavy precipitation has received relatively few analyses. Yasuda (1970) showed nocturnal high frequency of $\geq 50 \mathrm{~mm} / \mathrm{h}$ events over the country. This was in agreement with weather forecasters' experience that disastrous rainfall is more frequent in the nighttime. Okuta (1970) showed contrastive diurnal patterns of $\geq 20 \mathrm{~mm} / \mathrm{h}$ events between coastal and inland stations, which

Corresponding author: Fumiaki Fujibe, Meteorological Research Institute, Tsukuba 305-0052, Japan. E-mail: ffujibe@mri-jma.go.jp.

(C) 1999, Meteorological Society of Japan were characterized by morning and afternoon maxima, respectively. This result differs from the nocturnal maximum shown by Yasuda (1970), possibly because of the difference in precipitation thresholds. Tatehira and Hoshina (1993) analyzed regional features of the diurnal variation of $\geq 30 \mathrm{~mm} / \mathrm{h}$ events on the basis of average over each prefecture. However, their data period was only five years, corresponding to a hundred cases or less for a prefecture. A more comprehensive understanding of the diurnal variation of heavy precipitation requires an analysis based on various threshold values with an objective method of regionalization. It requires data for a longer period in order to achieve a higher degree of statistical reliability.

In all the studies cited above, and also in most of the similar studies in other countries (e.g., Wallace, 1975; Winkler et al., 1988), heavy precipitation was defined on the hour. However, Crysler et al. (1982) showed considerable difference in diurnal variation patterns according to the duration of precipitation events (from an hour to eight hours) in the central and eastern United States. A similar report was given by Jackson (1977) for the United Kingdom. Since serious rain hazards in Japan tend to be caused by long-lasting rainfall (several hours or more), it is worth while analyzing the diurnal variation of heavy precipitation defined on time scales longer than an hour. 

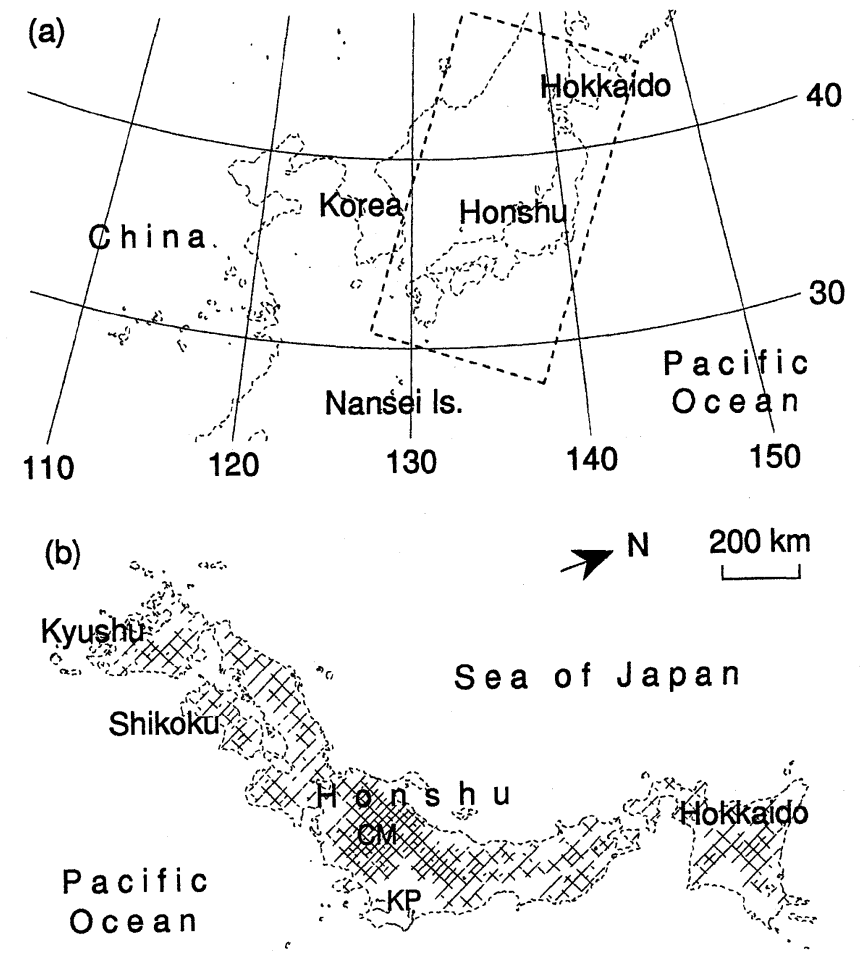

Fig. 1. (a) Map of eastern Asia. (b) Topography of the main analysis area (indicated by dashed lines in (a)). Hatching indicates the area above $200 \mathrm{~m}, 400 \mathrm{~m}, 800 \mathrm{~m}$ and $1600 \mathrm{~m}$ from the m.s.l. with increasing tones. $\mathrm{CM}=$ Central Mountains; $\mathrm{KP}=\mathrm{Kanto}$ plain.

We examine the diurnal variation of precipitation frequency in Japan defined on three time scales (one, three and six hours), and several threshold values ranging from moderate to very high intensities. The analysis is based on data for 18 years, which is longer than the data periods in previous studies. As heavy precipitation is rare and sporadic, its diurnal distribution at each station can be highly irregular. Our purpose is not to deal with such irregular features, but rather to find out some representative patterns with relation to regional characteristics. For this purpose, an objective classification scheme called the fuzzy $c$-means method (FCM; Bezdek, 1981; Sakawa, 1989) is applied. It has proved to be efficient in obtaining a small number of representative patterns in a sample of large population (Fujibe, 1989).

\section{Data and preliminary analysis}

\subsection{Data}

Hourly precipitation data from 1979 to 1996 were available from the AMeDAS (Automated Meteorological Data Acquisition System) network, with more than a thousand stations in Japan. Three- and six-hourly precipitations were calculated from these data. Stations at which the percentage of missing data exceeded $10 \%$ in any of the twelve months were not used. Site changes within $0.03^{\circ}$ in latitude and longitude were neglected (the value $0.03^{\circ}$ was given arbitrarily as it seemed to be almost in- different to the subsequent analysis). As a result, 980 stations were available for analysis. Time is in Japan Standard Time (JST).

\subsection{Thresholds of precipitation intensity}

The analysis was based on the frequency of events satisfying the following threshold values:

$5,10,20,30,40,50,60$ and $80 \mathrm{~mm} / \mathrm{h}$,

$10,20,40,60,80,100,120$ and $160 \mathrm{~mm} / 3 \mathrm{~h}$,

$20,40,80,120,160,200,240$ and $320 \mathrm{~mm} / 6 \mathrm{~h}$.

Hereafter the $r$-th threshold will be denoted by $P_{r}$, and the frequency of $\geq P_{r}$ events will be denoted by $f_{j i r}$, where $j$ is time of the day $(j=1-J ; J=24)$ and $i$ is station. The occurrence time was defined by the center of the definition period. For example, hourly precipitation between 11 JST and 12 JST was regarded to have occurred at $11.5 \mathrm{JST}$, and sixhourly precipitation between 07 JST and 13 JST was regarded to have occurred at 10 JST.

As shown later in Figs. 3-5, the lowest thresholds $\left(P_{r}=5 \mathrm{~mm} / \mathrm{h}, 10 \mathrm{~mm} / 3 \mathrm{~h}\right.$ and $\left.20 \mathrm{~mm} / 6 \mathrm{~h}\right)$ correspond to a frequency of the order of $10^{-2}$. Note that an event per year corresponds to a frequency of $1.14 \times 10^{-4}$.

The daily average of $f_{j i r}$ will be denoted by $\bar{f}_{i r}$. The normalized diurnal variation is defined by

$$
z_{j i r}=f_{j i r} \div \bar{f}_{i r} .
$$




\subsection{Smoothing with Fourier decomposition}

It is generally recognized that the diurnal precipitation variation shows a smooth curve which is sufficiently expressed by the lowest few harmonics. Before applying the FCM, data were smoothed by using Fourier series as:

$$
\begin{aligned}
f_{j i r}= & \bar{f}_{i r}\left\{1+\sum_{m=1}^{M}\left(c_{i r m} \cos \frac{m j \pi}{12}+s_{i r m} \sin \frac{m j \pi}{12}\right)\right. \\
& + \text { higher harmonics }\},
\end{aligned}
$$

or equivalently,

$$
\begin{aligned}
z_{j i r}= & 1+\sum_{\substack{m=1\\
}}^{M}\left(c_{i r m} \cos \frac{m j \pi}{12}+s_{i r m} \sin \frac{m j \pi}{12}\right) \\
& + \text { higher harmonics, }
\end{aligned}
$$

where $M=3$. The merit of Fourier smoothing is not only to reduce the data size and shorten the computation time, which was a few minutes by Sun's SPARK-2 workstation with Advanced Service I, but also to improve the statistical significance of the result (see 3.3).

\section{Classification of diurnal variation patterns with the FCM}

\subsection{Formulation}

The FCM differs from other methods of cluster analysis in that it allows for partial membership to more than one cluster. As discussed by Fujibe (1989), it has some advantage over other methods in analyzing data with large size, especially for obtaining a small number of representative patterns. It is defined by a least-squares problem

$$
\begin{aligned}
& \sum_{i=1}^{N} \sum_{k=1}^{K}\left(\underline{u}_{i k}^{p}{\underline{\sum_{r}}\left[W_{i r}\right.}_{\sum_{m=1}^{M}}\right. \\
& \left.\left.\left\{\left(c_{i r m}-C_{k r m}\right)^{2}+\left(s_{i r m}-S_{k r m}\right)^{2}\right\}\right]\right) \rightarrow \text { min., }
\end{aligned}
$$

with a condition

$$
\sum_{k=1}^{K} u_{i k}=1 \quad(\text { for each } i),
$$

where $C_{k r m}$ and $S_{k r m}$ are Fourier coefficients of the $k$-th cluster $(k=1-K), u_{i k}$ is the degree of membership of the $i$-th station to the $k$-th cluster, $p$ is a given constant larger than unity, $W_{i r}$ is a weight defined as shown below (Eq. (7)), and $N$ is the number of stations. The diurnal variation pattern of the $k$-th cluster, $Z_{j k r}$, is given by

$Z_{j k r}=1+\sum_{m=1}^{M}\left(C_{k r m} \cos \frac{m j \pi}{12}+S_{k r m} \sin \frac{m j \pi}{12}\right)$.
In comparison to the original form of FCM (Bezdek, 1981; Sakawa, 1989), (4) has an additional part shown by . This part was added in order to apply the method to more than one threshold, so that the classification might reflect the features for various intensities and durations. In practice, six thresholds were selected as described later in 3.4.

The weight $W_{i r}$ was given in the form

$$
W_{i r}=\bar{f}_{i r} \div \sum_{i=1}^{N} \bar{f}_{i r}
$$

which means that a station was weighted by its participation to the total frequency over all the stations.

\subsection{Solution}

The solution of (4) is given by

$$
\begin{aligned}
u_{i k}= & \left(\sum _ { r } \left[W _ { i r } \sum _ { m = 1 } ^ { M } \left\{\left(c_{i r m}-C_{k r m}\right)^{2}\right.\right.\right. \\
& \left.\left.\left.+\left(S_{i r m}-S_{k r m}\right)^{2}\right\}\right]\right)^{-\frac{1}{p-1}} \\
& \div \sum_{k=1}^{K}\left(\sum _ { r } \left[W _ { i r } \sum _ { m = 1 } ^ { M } \left\{\left(c_{i r m}-C_{k r m}\right)^{2}\right.\right.\right. \\
& \left.\left.\left.+\left(S_{i r m}-S_{k r m}\right)^{2}\right\}\right]\right)^{-\frac{1}{p-1}}
\end{aligned}
$$

and

$$
\begin{aligned}
C_{k r m} & =\sum_{i=1}^{N} u_{i k}{ }^{p} c_{i r m} \div \sum_{i=1}^{N} u_{i k}^{p}, \\
S_{k r m} & =\sum_{i=1}^{N} u_{i k}{ }^{p} s_{i r m} \div \sum_{i=1}^{N} u_{i k}{ }^{p} .
\end{aligned}
$$

This solution can be achieved by iteration starting from a random classification, and calculating (8)(10) in turn. If a pair of identical clusters are produced in the iteration, then one of them should be removed, and $K$ should be decreased by one. The final clusters obtained in this way are dependent only on $p$, and not on the initially assigned classification, unless $p$ is too small (Fujibe, 1989). The number of final clusters, $K_{\mathrm{final}}$, is also independent of the initial number of clusters $\left(K_{\text {initial }}\right)$, and tends to increase as $p$ decreases. The dependence of $K_{\text {final }}$ on $p$ in our analysis will be shown later in 4.1.

Once $u_{i k}$ is obtained, Eqs. (9) and (10) can be applied to other thresholds than are included in (4). Moreover, Eqs. (9) and (10) can be written as

$$
Z_{j k r}=\sum_{i=1}^{N} u_{i k}{ }^{p} z_{j i r} \div \sum_{i=1}^{N} u_{i k}{ }^{p}
$$

which is applicable to the original data containing higher harmonics. Eq. (11) can be also written in the form 


$$
Z_{j k r}=F_{j k r} \div \bar{F}_{k r}
$$

where $F_{j k r}$ and $\bar{F}_{k r}$ are absolute frequency of $\geq P_{r}$ events for the $k$-th cluster defined by

$$
F_{j k r}=\sum_{i=1}^{N} u_{i k}^{p} f_{j i r} \div \sum_{i=1}^{N} u_{i k}^{p}
$$

and

$$
\bar{F}_{k r}=\sum_{i=1}^{N} u_{i k}{ }^{p} \bar{f}_{i r} \div \sum_{i=1}^{N} u_{i k}^{p},
$$

respectively.

\subsection{Evaluation of statistical significance}

A reliable evaluation of statistical significance requires a statistically independent sampling. $\quad F_{j k r}$ was calculated separately for each year, because its yearly values were reasonably expected to form an independent data set. Likewise, $\bar{F}_{k r}$ was obtained for each year. If we denote their yearly values by $F_{j k r n}$ and $\bar{F}_{k r n}$, where $n$ is year, and the variances and covariance of their year-to-year variations by $V_{j k r}, \bar{V}_{k r}$ and $v_{j k r}$, respectively, then the standard error of $Z_{j k r}$ (hereafter $\sigma_{j k r}$ ) is given by

$\sigma_{j k r}=\frac{F_{j k r}}{\bar{F}_{k r}} \sqrt{\left(\frac{V_{j k r}}{F_{j k r}}\right)^{2}+\left(\frac{\bar{V}_{k r}}{\bar{F}_{k r}}\right)^{2}-\frac{v_{j k r}}{F_{j k r} \bar{F}_{k r}}}$

on the conditions $V_{j k r} \ll F_{j k r}$, and $\bar{V}_{k r} \ll \bar{F}_{k r}$ (Hald, 1952). Another estimation of $\sigma_{j k r}$ can be made by an error matrix of the least-squares method, because $Z_{j k r}$ is the solution to a leastsquares problem

$$
\sum_{n=1979}^{1996} \bar{F}_{k r n}\left(Z_{j k r n}-Z_{j k r}\right)^{2} \rightarrow \text { Min., }
$$

where $Z_{j k r n}=F_{j k r n} \div \bar{F}_{k r n}$. The values of $\sigma_{j k r}$ obtained from the two methods are in satisfactory agreement, except for very rare events $\left(F \lesssim 10^{-5}\right)$. The error bars shown in the following figures indicate the larger of the $\sigma_{j k r}$ values obtained from (15) and (16).

These methods can be applied to both the results obtained from the smoothed data and the original data. The Fourier smoothing does not affect the independence of yearly values. The smoothed data can achieve a higher statistical significance (smaller $\sigma_{j k r}$ ) than the original data, which involves yearly fluctuations arising from higher harmonics.

\subsection{Practice in application}

Some test calculations revealed that the peculiar diurnal variation in the Nansei Islands affected the classification of diurnal patterns in the whole country. A better regionalization was achieved by excluding the Nansei Island stations. The FCM analysis was made for the 952 stations located north of $30^{\circ} \mathrm{N}$ (namely $N=952$ in Eq. (4)). The remaining 28 stations in the Nansei Islands were separately analyzed.

As for the precipitation thresholds used for classification, the following six were selected:

$$
\begin{aligned}
P_{r}= & 5 \mathrm{~mm} / \mathrm{h}, 10 \mathrm{~mm} / \mathrm{h}, 20 \mathrm{~mm} / \mathrm{h} ; \\
& 20 \mathrm{~mm} / 6 \mathrm{~h}, 40 \mathrm{~mm} / 6 \mathrm{~h} \text { and }, 80 \mathrm{~mm} / 6 \mathrm{~h} .
\end{aligned}
$$

The diurnal variations for other thresholds were obtained by using Eqs. (11)-(14). This was because the diurnal variation patterns of three-hourly precipitation were essentially a compound of hourly and six-hourly precipitation (as shown later in Chapter 4). Diurnal variations for higher thresholds were more irregular among stations due to a smaller number of events. There may be some concern about the applicability of classification based on the low thresholds to those for higher ones, but the obtained diurnal patterns showed systematic differences among clusters for all the thresholds. We accept this procedure as satisfactory, in view of the absence of a better way of classification.

\section{Results}

\subsection{Outline of the FCM classification}

The number of clusters $\left(K_{\text {final }}\right)$ obtained from the FCM analysis was dependent on $p$ in the following manner:

$$
p \quad 2.52 .22 .01 .81 .61 .51 .45 \quad<1.45 \text {, }
$$

$\begin{array}{lllllllll}K_{\text {final }} & 1 & 3 & 3 & 4 & 3 & 5 & 6 & \text { not unique. }\end{array}$

Thus the maximum number of clusters is six, corresponding to $p=1.45$. Our following analysis is based on these six clusters. They are numbered in the order of the contribution factor $B_{k}$ defined by:

$$
B_{k}=\frac{\sum_{i=1}^{N} u_{i k}\left(\sum_{r} \bar{f}_{i r}\right)}{\sum_{i=1}^{N} \sum_{r} \bar{f}_{i r}},
$$

which has following values:

$$
\begin{array}{ccccccc}
k & 1 & 2 & 3 & 4 & 5 & 6 \\
B_{k}(\%) & 19.7 & 18.6 & 18.4 & 18.3 & 17.0 & 8.0 .
\end{array}
$$

In addition to these six clusters, the areal average pattern was obtained by putting $u_{i k}=1$ in Eqs. (9)(14). This pattern is identical to the single cluster obtained for $p \geq 2.5$. The average pattern for the Nansei Islands was calculated in the same way.

\subsection{Regional characteristics}

Before showing the diurnal variation patterns of the six clusters, we examine their spatial distribution. Figure 2 shows the dominant cluster at each station defined by the largest value of $u_{i k}$ among the six. 


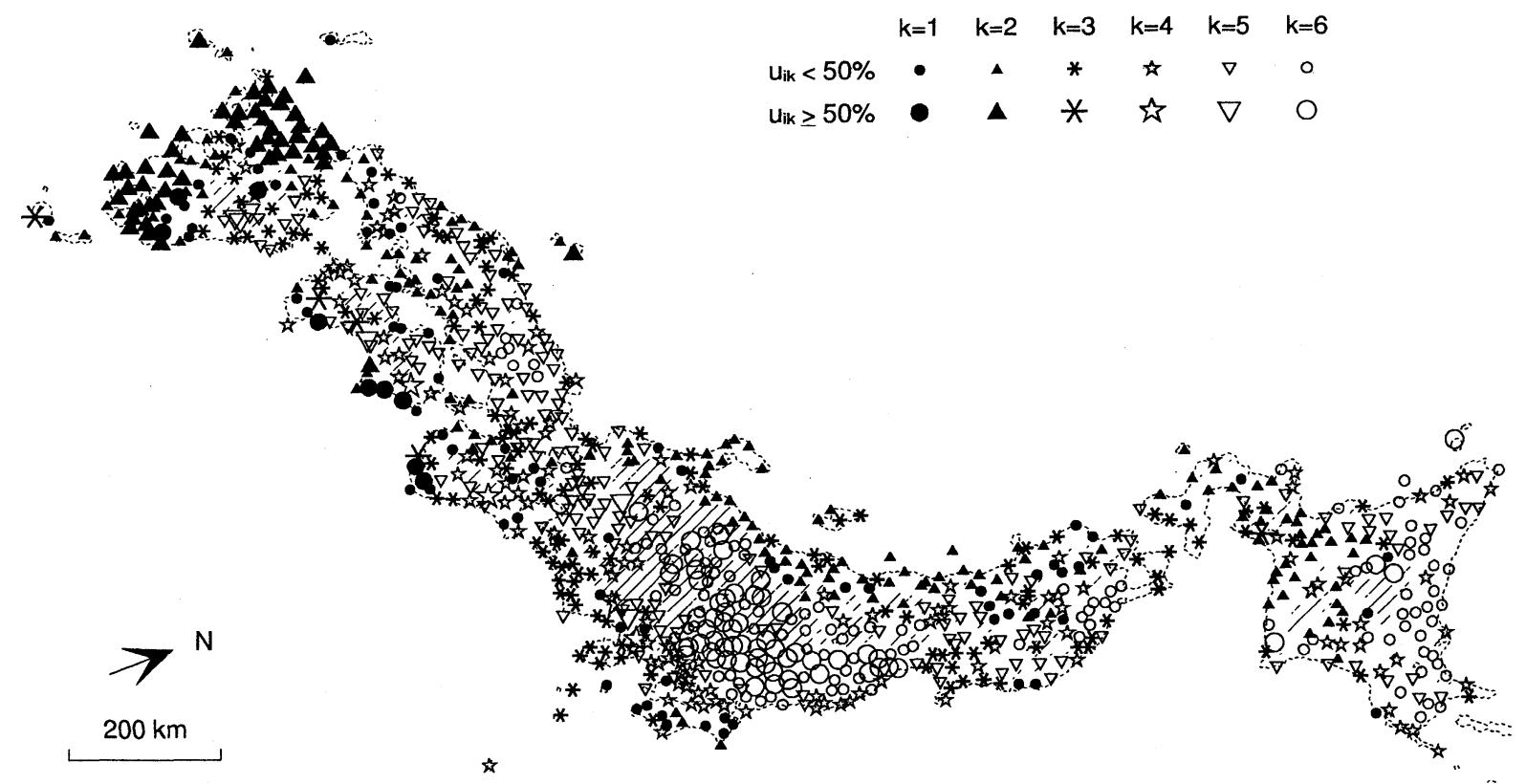

Fig. 2. Distribution of the dominant cluster defined by the largest value of $u_{i k}$ among the six. Hatching indicates the area above $800 \mathrm{~m}$ from the m.s.l.

The first two clusters $(k=1$ and 2$)$ prevail in the coastal regions. The cluster $k=1$ is mainly found on the southern coasts of Honshu and Shikoku, while $k=2$ dominates on the western part of Kyushu, the northwestern coast of Honshu and the southwestern part of Hokkaido. The next two $(k=3$ and 4) are mainly found on the Pacific side of land. The cluster $k=3$ is most prevalent on the southern side of the mountainous regions, and plains thrusting northward, while $k=4$ prevails on the eastern and southeastern sides of the mountain regions. The last two clusters $(k=5$ and 6$)$ prevail in inland regions. The cluster $k=6$ is dominant from the Central Mountain region to its eastern side, including the northern part of the Kanto plain, as well as the northwestern side of Hokkaido, while $k=5$ is mainly found in other inland regions.

\subsection{Diurnal variation patterns}

Figure 3 shows the diurnal variation patterns for seven thresholds from $P_{r}=5 \mathrm{~mm} / \mathrm{h}$ to $P_{r}=$ $60 \mathrm{~mm} / \mathrm{h}$. In order to display the absolute frequency $\left(F_{j k r}\right.$ and $\left.\bar{F}_{k r}\right)$ and the normalized diurnal variation $\left(Z_{j k r}\right)$ simultaneously, a logarithmic scale is used. Note that the error bars indicate those for $Z_{j k r}$, namely $\sigma_{j k r}$ defined in 3.3, and not for $F_{j k r}$.

The diurnal variation for $P_{r}=5 \mathrm{~mm} / \mathrm{h}$ is generally weak; the deviation of hourly frequency from the daily mean is $30 \%$ at most. The areal average pattern is bimodal with maxima in the morning (05-06 JST) and afternoon (16-17 JST), and minima in midday (11-12 JST) and late evening (21-22 JST). This feature is essentially common to the six clusters. The intensities of morning and afternoon maxima differ among them. The morning maximum is highest for $k=2$ and decreases in the order of $k=1,3,4,5,6$, while the afternoon maximum increases in the same order. In this respect, $k=2$ and $k=6$ are the extreme patterns.

For higher thresholds, diurnal variation tends to intensify with some changes in patterns. These changes can be summarized as: (a) increasing morning peaks for $k=1$ and 2, (b) increasing evening peaks for $k=5$ and 6 , and (c) decreasing morning peaks replaced by increasing frequency from evening to midnight for $k=3$ and 4 , and implicitly for $k=5$ and 6 . As for the areal average, the morning maximum and the late evening minimum weakens toward higher thresholds, while the late afternoon maximum and the midday minimum intensifies.

Figure 4 shows the result for three-hourly precipitation. The diurnal patterns for the lowest threshold $\left(P_{r} \geq 10 \mathrm{~mm} / 3 \mathrm{~h}\right)$ are quite similar to that of $P_{r} \geq 5 \mathrm{~mm} / \mathrm{h}$. For higher thresholds, the diurnal patterns differ from those of hourly precipitation with respect to: (A) stronger morning maximum for $k=1$ and 2 , (B) weaker afternoon maximum for $k=5$ and 6 , and (C) more conspicuous increase in midnight frequency for $k=3-6$, especially for $k=3$ and 5 . The areal average pattern is characterized by a single minimum in midday, with nearly uniform frequency during the night, while the afternoon peak is lacking unlike hourly precipitation.

Figure 5 shows the result of six-hourly precipitation. For the lowest threshold $\left(P_{r} \geq 20 \mathrm{~mm} / 6 \mathrm{~h}\right)$, the morning maximum is slightly stronger. Afternoon maximum is weaker in comparison to the $P_{r} \geq 5 \mathrm{~mm} / \mathrm{h}$ and $P_{r} \geq 10 \mathrm{~mm} / 3 \mathrm{~h}$ cases. For higher thresholds, the diurnal patterns change in the same way as observed for three-hourly precipitation 


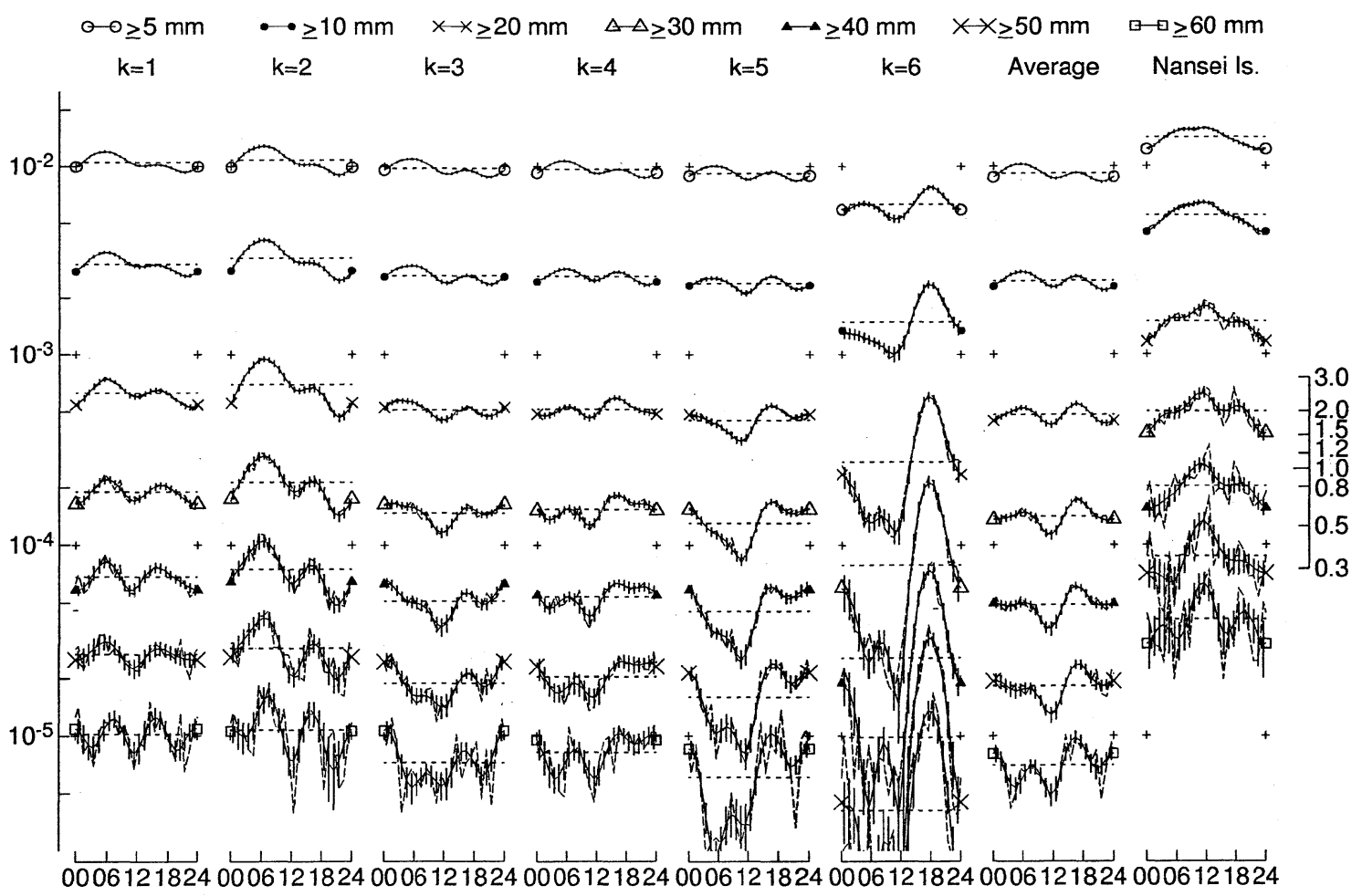

Fig. 3. Diurnal variation in the frequency of hourly precipitation events. The daily mean frequency $\left(\bar{F}_{k r}\right)$ is shown in a dotted line. The values obtained from the smoothed data (Eqs. (2) and (3)) are shown in a solid line with vertical bars, which indicate the range of standard error of $Z_{j k r}$ calculated in the procedure described in 3.3. The values obtained from the original data are shown in a thin dashed line. The scale on the left side indicates absolute frequency (for $F_{j k r}$ and $\bar{F}_{k r}$ ), while that on the right side gives the measure of normalized diurnal variation (for $Z_{j k r}$ ).

(A-C in the previous paragraph), with a stronger tendency for a nocturnal maximum.

It can be seen from Figs. 3-5 that diurnal variations calculated from the original $F_{j k r}$ values do not show essential difference from those obtained from the smoothed data except for some deviation for high thresholds. This fact confirms that the average diurnal variation among many stations (of the order of a hundred in number) is sufficiently smooth that it can be expressed by the lowest three harmonics.

\section{Supplementary analyses}

\subsection{Analysis based on equal sampling}

Since the frequency of heavy precipitation is not spatially uniform, our result may largely reflect the features of some stations where precipitation is more frequent than others. It is therefore interesting to make another analysis, in which each station has an equal weight. Here we present the result of analysis in which an equal number of cases were taken from each station in the descending order of precipitation intensity.

Figure 6 shows the results for $k=2,6$, and the areal average obtained in this way. We can see that the main features in Figs. 3-5 are retained. Afternoon peaks are somewhat more conspicuous in
Fig. 6a than in Fig. 3. The features shown in Figs. 35 are not very sensitive to the spatial inhomogeniety in precipitation frequency.

\subsection{Diurnal variation of probability precipitation in- tensity}

Instead of the frequency of events satisfying an intensity threshold, it is possible to define probability precipitation intensity (PPI) as the intensity of precipitation which is expected to occur at a given frequency. Here we briefly compare the diurnal variation in PPI with that of frequency.

Evaluation of PPI requires expressing the relation of precipitation intensity and frequency (hereafter $P$ and $F$, respectively), with the latter as the independent variable. A statistical theory of extreme values gives a suggestion as to what functional form is suitable for this purpose. In the limit $P \rightarrow \infty$, the $P-F$ relationship should have an asymptotic form of either the Fisher-Tippett Type I;

$$
F=1-\exp \{-\exp (-a P-b)\},
$$

or the Type II;

$$
F=1-\exp \left(-a P^{-b}\right),
$$

where $a$ and $b$ are unknown parameters (Essenwanger, 1986; Suzuki, 1992). Equation (18) indicates a linear relation between $P$ and 


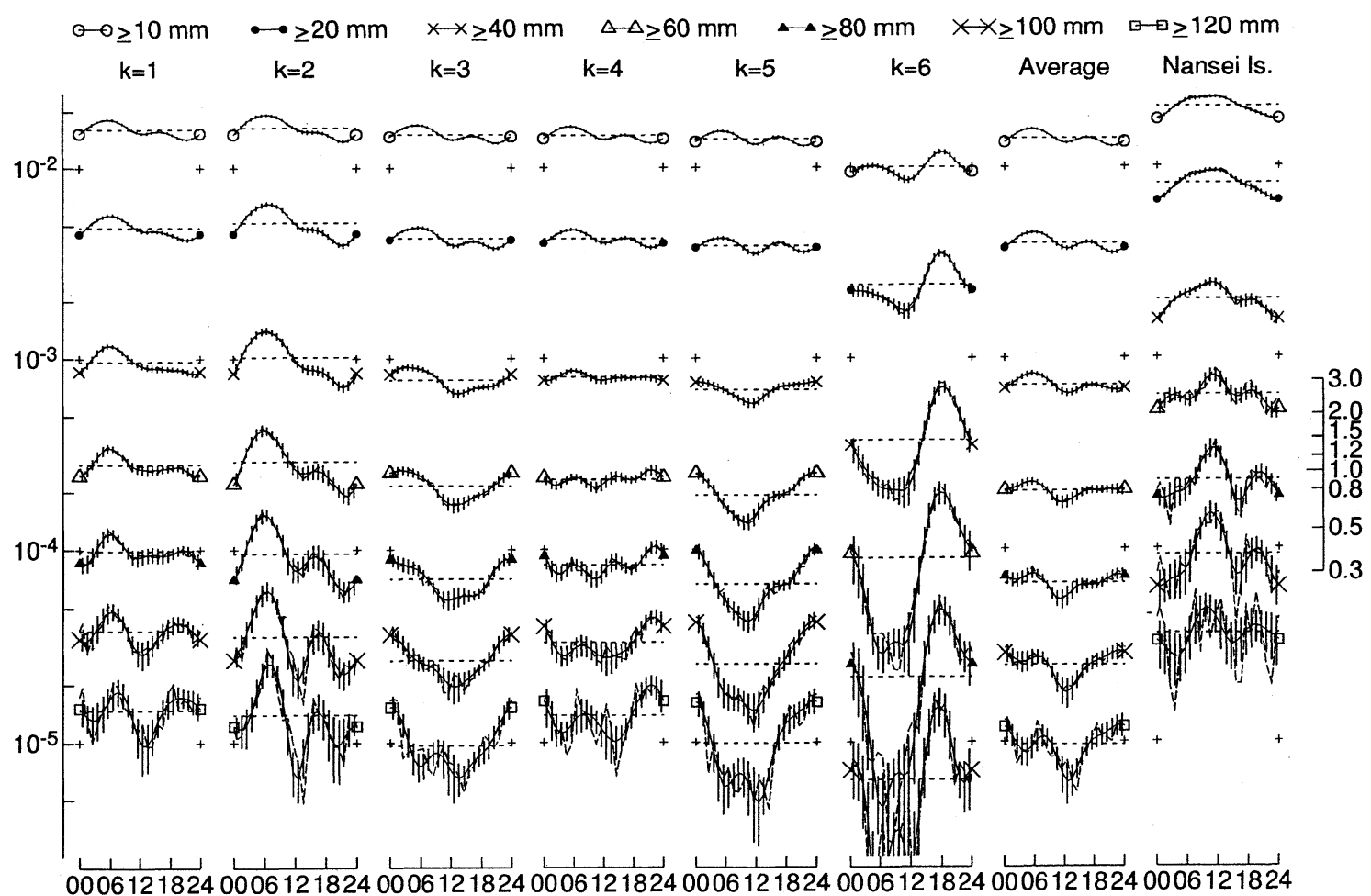

Fig. 4. Same as Fig. 3 but for three-hourly precipitation.

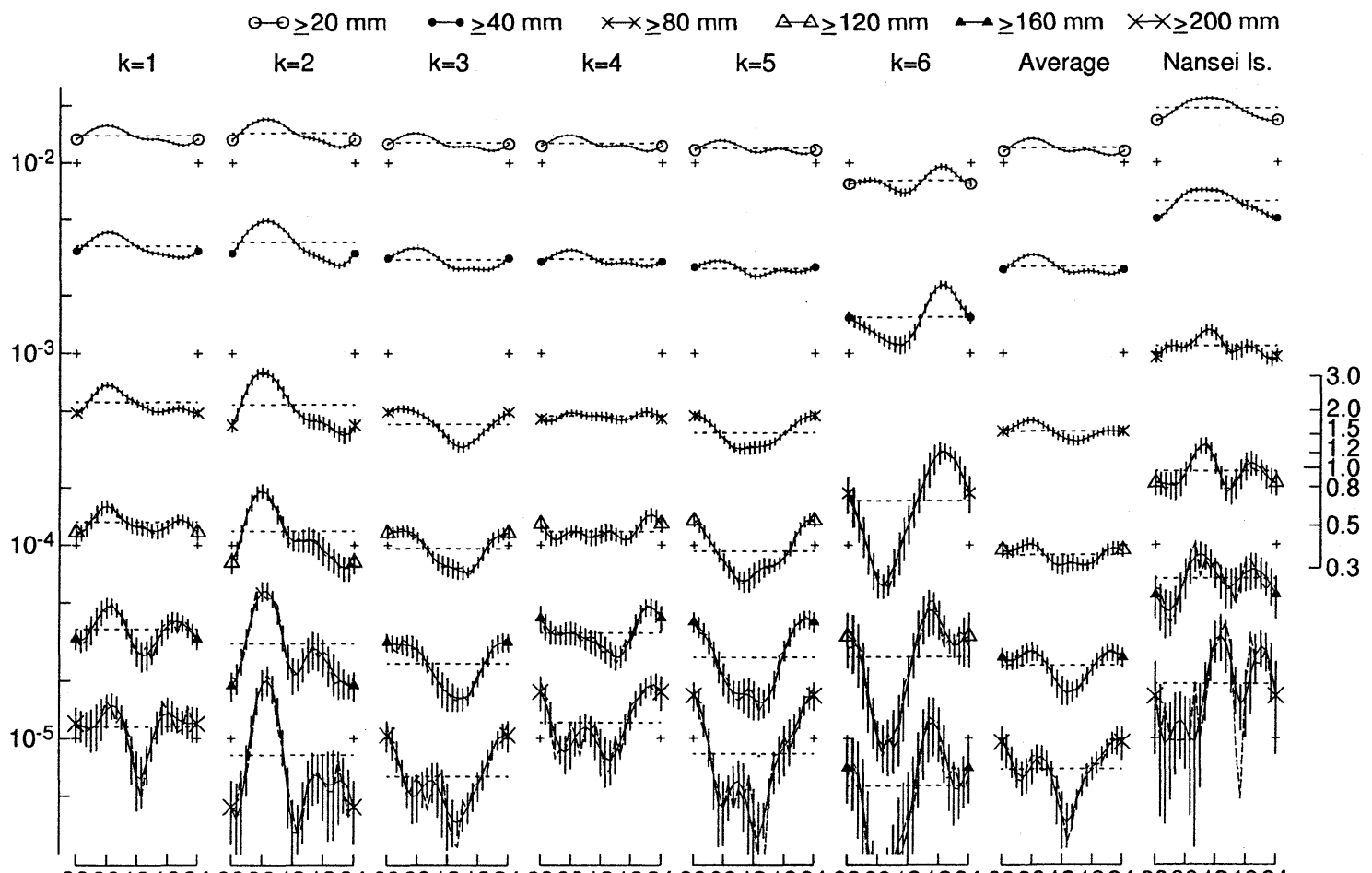

00061218240006121824000612182400061218240006121824000612182400061218240006121824

Fig. 5. Same as Fig. 3 but for six-hourly precipitation.

$\log \{-\log (1-F)\}$, which can be replaced by $\log F$ if $|F| \ll 1$. This implies approximate linearity between $P$ and $\log F$, although some nonlinearity is likely if $P$ is not sufficiently large. Our analysis was therefore based on Akima's (1970) cubic spline functions in the $P-\log F$ domain, namely

$$
P=c_{0}+c_{1} \log F+c_{2}(\log F)^{2}+c_{3}(\log F)^{3},
$$

where $c_{0}-c_{3}$ are coefficients which were determined separately for each interval between neighboring thresholds.

Figure 7 shows the daily mean $P-\log F$ rela- 


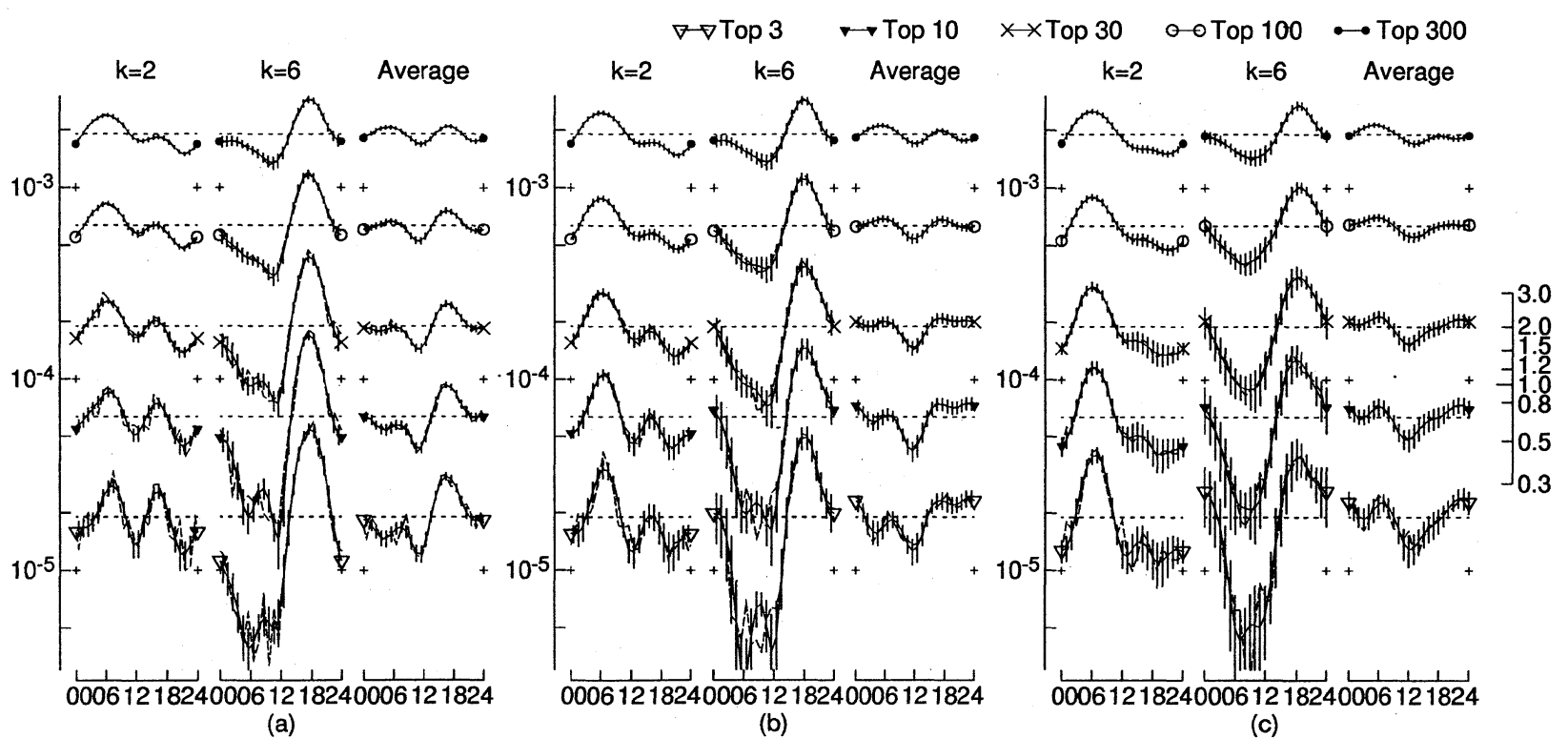

Fig. 6. Diurnal variation obtained from a specified number of leading events at each station for (a) hourly, (b) three-hourly and (c) six-hourly precipitation.

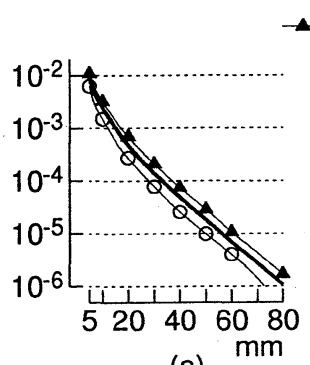

(a)

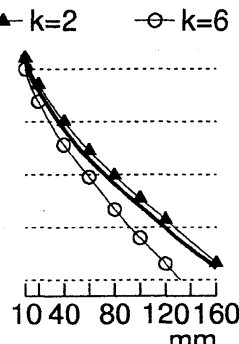

(b)

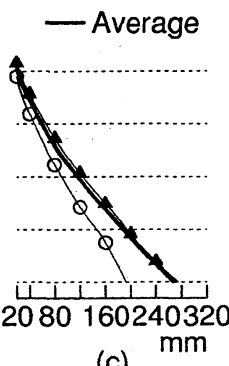

(c)

Fig. 7. Relationship between precipitation intensity (abscissa) and frequency (ordinate) for (a) hourly, (b) three-hourly and (c) six-hourly precipitation.

tionship for $k=2, k=6$, and the areal average obtained by applying (20) to the $\bar{F}_{k r}$ values in the previous chapter. It can be seen that $\bar{F}=10^{-3}$ corresponds to $P=10-20 \mathrm{~mm} / \mathrm{h}, P \approx 40 \mathrm{~mm} / 3 \mathrm{~h}$ and $P=40-80 \mathrm{~mm} / 6 \mathrm{~h}$, and $\bar{F}=10^{-5}$ corresponds to $P \approx 60 \mathrm{~mm} / \mathrm{h}, P \approx 120 \mathrm{~mm} / 3 \mathrm{~h}$ and $P=160-200 \mathrm{~mm} / 6 \mathrm{~h}$. Each curve in Fig. 7 is sufficiently smooth that a cubic interpolation is justified. It is to be noted that a similar analysis in the $\log P-\log F$ domain, where a linear relationship is expected if (19) holds instead of (18), also results in a smooth fitting (not shown) with only a slight difference $(\sim 1 \mathrm{~mm}$ or less) in interpolated $P$ values from those given by $(20)$.

Figure 8 shows the diurnal variation of PPI for $F=10^{-3}, 10^{-4}$ and $10^{-5}$ obtained from similar interpolation based on hourly $F_{j k r}$ values. The ordinate is scaled in logarithm for the same reason as in Figs. 3-5, so that the the scales on the left and right sides give the absolute and normalized

values, respectively. Note that error bars indicate those of normalized values, namely the range corresponding to $\bar{F}_{k r}\left(Z_{j k r} \pm \sigma_{j k r}\right)$, and not of absolute PPI values. Comparison of Fig. 8 and Figs. $3-5$ reveals that PPI shows a smaller normalized amplitude than frequency, especially for rare events (low frequency and high PPI). The large diurnal variation in the frequency of heavy precipitation events is in fact associated with a relatively small variation in the heaviness of precipitation that occurs at a given frequency.

\subsection{Seasonal difference}

The diurnal variation patterns may differ according to seasons, due to difference in the solar angle and/or prevailing weather conditions. This possibility was briefly examined.

Figure 9 shows the annual variation of areal average frequency of precipitation events. Both for hourly and six-hourly precipitation, the annual variation has a unimodal pattern with a higher frequency in the warmer half year (May-October). The synoptic climate of this half year can be divided into three periods. Until the middle of July, the baiu front plays a major role in causing heavy rainfall, especially in the western part of Japan. The midsummer period from late July to August is a relatively dry season under the influence of the subtropical high, but afternoon thunderstorms often develop over the land, and typhoons occasionally cause heavy rainfall. September and early October is the shurin season, in which a frontal zone (shurin front) tends to lie from Honshu to Kyushu, and heavy rainfall sometimes occurs in the presence of a typhoon. However, these seasonal changes are not very dis- 


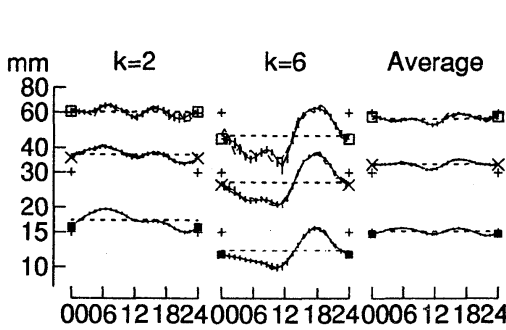

(a)

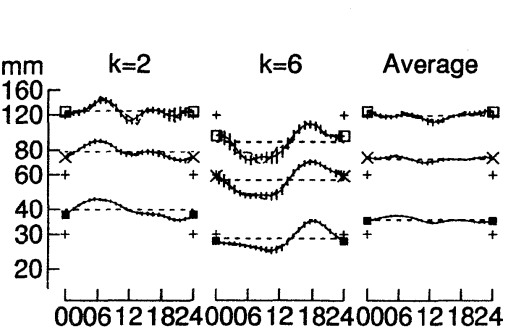

(b)

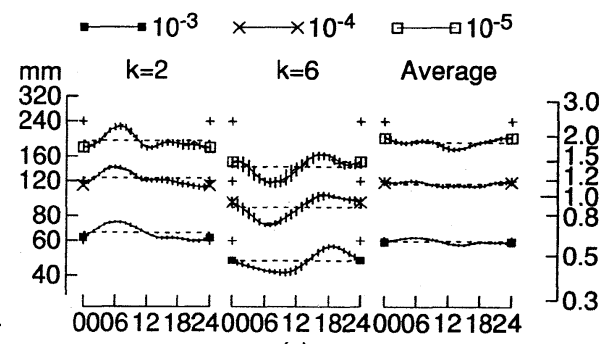

(c)

Fig. 8. Diurnal variation of probability precipitation intensity (PPI) for (a) hourly, (b) three-hourly and (c) six-hourly precipitation. The scale on the left side indicates absolute precipitation intensity, while that on the right side gives the measure of normalized diurnal variation.

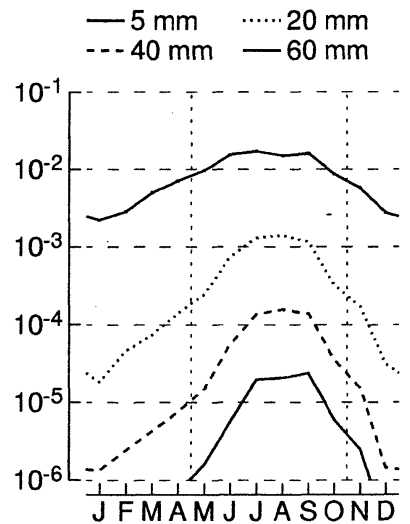

(a)
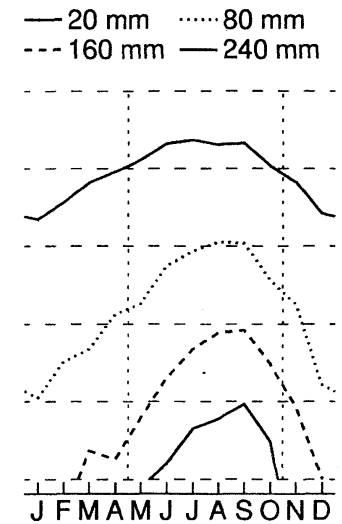

(b)
Fig. 9. Annual variation of daily mean precipitation frequency for (a) hourly and (b) six-hourly precipitation.

tinct, but show considerable interannual, and intraseasonal variations. In our analysis, the half year was divided simply into three two-month periods: May-June; July-August; and, September-October.

Figures 10 and 11 show the results for hourly and six-hourly precipitation, respectively, based on $f_{j i r}$ values obtained for each period. The diurnal variation patterns for the three periods have an essential resemblance to one another, apart from some differences found at places. A widely observed difference is a weaker morning maximum in SeptemberOctober than the other two, but it is not our intention to enter into details of these differences.

Figure 12 shows the correlation coefficients of $Z_{j k r}$ values between each pair of two-month periods, namely

$$
\begin{aligned}
& \rho_{r}(\alpha, \beta)= \\
& \sum_{k=1}^{K} \sum_{m=1}^{M}\left(C_{k r m, \alpha} C_{k r m, \beta}+S_{k r m, \alpha} S_{k r m, \beta}\right) \\
& \div\left\{\sum_{k=1}^{K} \sum_{m=1}^{M}\left(C_{k r m, \alpha}^{2}+S_{k r m, \alpha}^{2}\right)\right\} \\
& \times\left\{\sum_{k=1}^{K} \sum_{m=1}^{M}\left(C_{k r m, \beta}^{2}+S_{k r m, \beta}^{2}\right)\right\},
\end{aligned}
$$

where $\alpha$ and $\beta$ denote periods. There is positive correlation for the lower thresholds, reflecting the basic similarity between periods. In particular, the correlation between May-June and July-August tends to be higher than the other two pairs, due to the high resemblance of their diurnal patterns. On the other hand, correlation tends to decrease as $P_{r}$ increases. This indicates larger seasonal differences for heavier precipitation. It may result from statistical fluctuation arising from a small sample size of extreme cases, rather than to reflect a physical fact.

\section{Discussion}

To summarize our results, the diurnal variation of heavy precipitation in Japan can be classified into following patterns according to regions:

(a) A morning maximum prevails in coastal regions $(k=1,2)$, especially on the western side of land $(k=2)$.

(b) A broad maximum around midnight is found in most of the other regions, especially the southern and eastern sides of mountainous regions $(k=3,4)$, and part of the inland region $(k=5)$.

(c) A late afternoon maximum is dominant in part of the inland area, especially to the east of large mountain regions $(k=6)$. A weak maximum in the late afternoon is found for other regions as well.

(d) A daytime maximum prevails over the Nansei Islands.

Many of these features agree with those found for precipitation amount, and the frequency of weaker precipitation (Fujibe, 1988; Tagami, 1990; Oki and Musiake, 1994). However, the midnight maximum in (b) is peculiar to heavy precipitation in the present analysis, especially three- and six-hourly one, instead of the morning maximum prevalent in weak precipitation. In addition, the late afternoon maximum is relatively more evident for heav- 


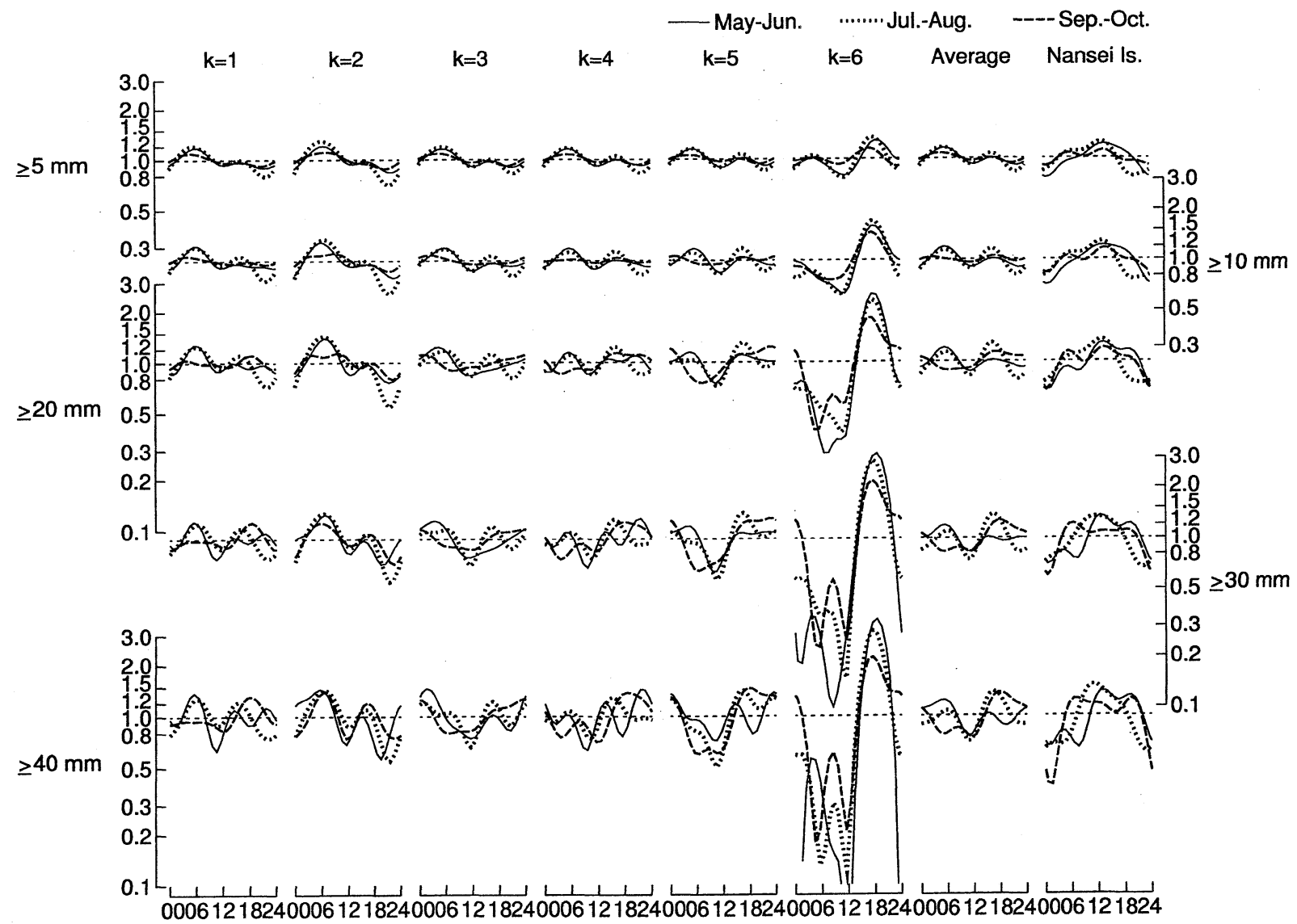

Fig. 10. Normalized diurnal variation of hourly precipitation events for each two-month period.

ier events. In the following, we give some discussion on the interpretation of these results.

\section{(a) Morning maximum}

Morning maxima in convective precipitation and cloudiness are widely found over maritime regions of tropics and middle latitudes in the warm season (Hann, 1901; Gray and Jacobson, 1977; Murakami, 1983; Fu et al., 1990; Hendon and Woodberry, 1993; Nitta and Sekine, 1994; Janowiak et al., 1994). Detailed analyses in these studies show that the morning maximum tends to be more pronounced for deeper clouds than shallower ones. It is more conspicuous in areas adjacent to land than over the open ocean, and more evident on the upwind side of land than on the downwind side, namely on the western coast in the middle latitudes. Our results for coastal regions conform to these features.

The reason for the morning maximum is still open to discussion, but it is believed that radiative forcing is important in regulating cloud activity (Randall et al., 1991; Miller and Frank, 1993; Xu and Randall, 1995; Bergman, 1997). On a smaller scale, land and sea breezes may also contribute to the diurnal precipitation cycle in coastal regions, as observed in some tropical regions (Houze et al., 1981). However, land breezes along the coasts of Japan are very weak and shallow in the warm season, while radar and satellite data indicate the existence of morning maximum in some offshore areas a few hundred kilometers away from land (Misumi, 1999; Takeda and Iwasaki, 1987; Kurihara and Kato, 1997). It is highly unlikely that the cloud activity in these areas is influenced by land breezes.

\section{(b) Midnight maximum}

In comparison to the widespread morning maximum, examples of midnight precipitation maximum are relatively few (e.g., Wallace, 1975). However, our result agrees with those of Crysler et al. (1982) and Jackson (1977) with respect to nocturnal high frequency of heavy precipitation with a long time scale (4-8 hours). Mesoscale convective complexes (MCCs) have a tendency to develop in the nighttime over many land areas of the world (Maddox, 1980; McAnelly and Cotton, 1989; Augustine and Howard, 1991; Laing and Fritsch, 1993a, b; Kato et al., 1995), although the peak time scatters between early evening and early morning. These facts suggest that the nocturnal maximum may be characteristic to long-lasting heavy precipitation over many land regions.

At present we do not find a satisfactory explanation for the midnight maximum. The. United States nocturnal MCCs are sometimes discussed with relation to a southerly low-level jet, which di- 


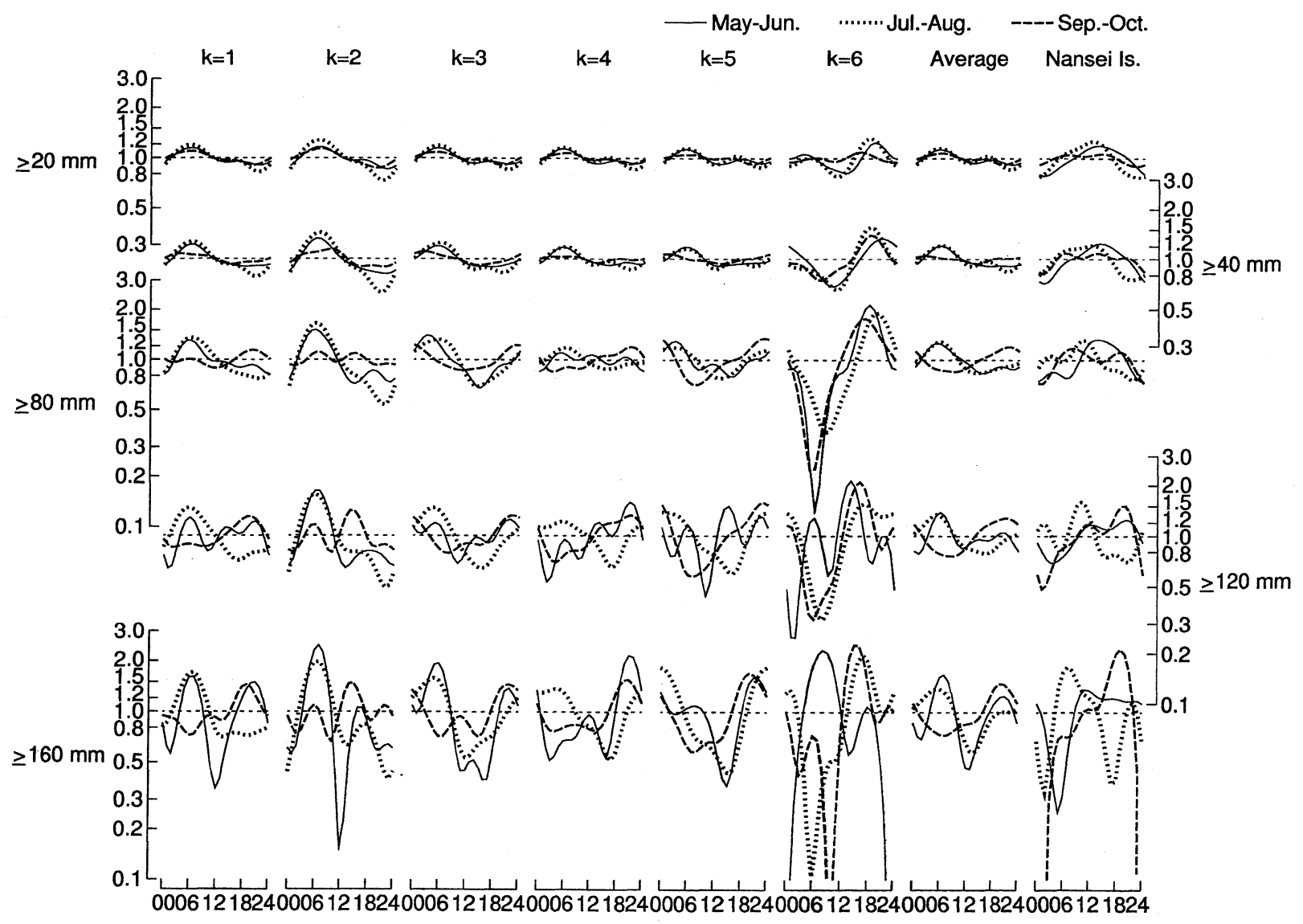

Fig. 11. Same as Fig. 10 but for six-hourly precipitation.

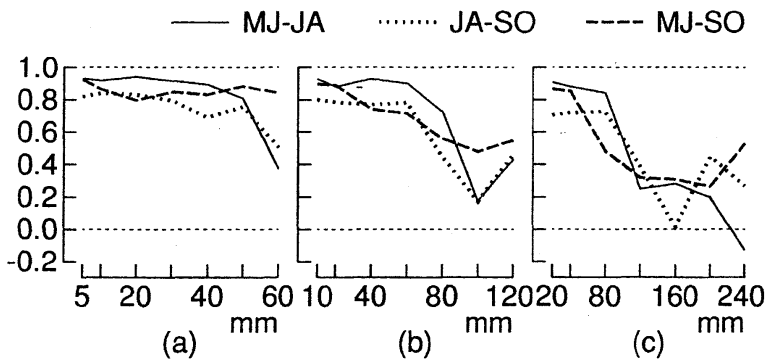

Fig. 12. Correlation coefficients of diurnal variation patterns (Eq. (21)) for each pair of two-month periods.

urnally oscillates with a peak intensity around midnight (Wallace, 1975; McCorcle, 1988; Nicolini et al., 1993). It is not certain whether a similar explanation applies to Japan. On a smaller scale, nighttime precipitation maximum observed in some deep basins has been discussed with relation to lowlevel convergence associated with local circulations (Prasad, 1974; Tucker, 1993). In the Central Mountain region of Japan, however, precipitation activity is accompanied by a phase difference of only a few hours between mountains and basins (Fujibe, 1988; Saitoh and Kimura, 1998). In our result local circulations are likely to be of minor effect on the midnight maximum.
Our finding agrees with the empirical knowledge of weather forecasters on the nighttime high frequency of disastrous rainfall. Our analysis has revealed that the midnight maximum is more conspicuous for three- and six-hourly precipitation, which involves a higher danger of rainfall disasters than hourly precipitation.

\section{(c) Late afternoon maximum}

Afternoon maxima of convective precipitation is a widespread feature over the land. Our analysis shows that the afternoon maximum is more conspicuous for heavier precipitation with a shorter time scale. This fact agrees with our experience that afternoon showers often cause severe localized rainfall, although they usually cease within an hour or so.

The afternoon peak is most striking for $k=6$, which prevails in the eastern part of the Central Mountain region and the northern Kanto plain. This agrees with the fact that afternoon thunderstorms tend to develop into organized mesoscale systems in this region. However, absolute frequency of heavy precipitation is much lower for $k=6$ than for other clusters on the daily average, as seen from Figs. 3-5. The region of central Honshu dominated by $k=6$ largely overlaps with the rain shadow of the Central Mountains under southwesterly prevailing winds (Fujibe, 1989). This indicates that the shel- 
tering effect of the Central Mountains weakens cloud systems approaching from the west, and enhances the relative contribution of diurnally triggered convections.

\section{(d) Midday maximum over the Nansei Islands}

The midday maximum over the Nansei Islands was found in previous studies. It contradicts with the general feature of maritime precipitation characterized by a morning maximum. Fujibe (1988) and Tagami (1990) showed that the midday maximum in this region was more conspicuous at large islands than at small ones. This suggests that daytime heating of islands is a cause of the midday maximum, as in the study of Gray and Jacobson (1977) for tropical oceans. This effect is also recognized in the deep clouds of typhoons passing the Nansei Islands, where an early afternoon maximum emerges in the cloud coverage in addition to the prevalent morning maximum (Muramatsu, 1983). According to radar echo statistics of Misumi (1999), however, the region of midday maximum spreads far into the surrounding sea area for more than a hundred kilometers, with phase lagging toward the southeast. The explanation to the midday maximum is still open.

\section{Acknowledgments}

AMeDAS data were obtained from magnetic tapes compiled by the Observations Department of the JMA, partly through the Computer Room of the Meteorological Research Institute (MRI).

\section{References}

Akima, H., 1970: A new method of interpolation and smooth curve fitting based on local procedures. $J$. Assoc. Comput. Mach., 17, 589-602.

Augustine, J.A. and K.W. Howard, 1991: Mesoscale convective complexes over the United States during 1986 and 1987. Mon. Wea. Rev., 119, 1575-1589.

Bergman, J.W., 1997: A numerical investigation of cloud diurnal variations. J. Climate, 10, 2330-2350.

Bezdek, J.C., 1981: Pattern recognition with fuzzy objective function algorithms. Plenum Press, 256pp.

Crysler, K.A., R.A. Maddox, L.R. Hoxit and B.M. Muller, 1982: Diurnal distribution of very heavy precipitation over the central and eastern United States. Natl. Wea. Dig., 7, 33-37.

Essenwanger, O.M., 1986: World Survey of Climatology, Vol. 1B: Elements of Statistical Analysis. Elsevier, 424pp., 75-89.

Fu, R., A.D. Del Genio and W.B. Rossow, 1990: Behavior of deep convective clouds in the tropical Pacific deduced from ISCCP radiances. J. Climate, 3, 11291152.

Fujibe, F., 1988 : Diurnal variations of precipitation and thunderstorm frequency in Japan in the warm season. Pap. Meteor. Geophys., 39, 79-94.

Fujibe, F., 1989: Short-term precipitation patterns in central Honshu, Japan. -Classification with the fuzzy $c$-means method. J. Meteor. Soc. Japan, 67, 967-983.

Gray, W.M. and R.W. Jacobson, 1977: Diurnal variation of deep cumulus convection. Mon. Wea. Rev., 105, 1171-1188.

Hald, A., 1952: Statistical theory with engineering applications. John Wiley \& Sons, 498-499.

Hann, J. von, 1901: Lehrbuch der Meteorologie. Verlag von Chr. Herm. Tauchnitz, 329-338, 657-662.

Hendon, H.H. and K. Woodberry, 1993: The diurnal cycle of tropical convection. J. Geophys. Res., 98, 16623-16637.

Houze, R.A., Jr., S.G. Geotis, F.D. Marks, Jr. and A.K. West, 1981: Winter monsoon convection in the vicinity of north Borneo. Part I: Structure and time variation of the clouds and precipitation. Mon. Wea. Rev., 109, 1595-1614.

Jackson, M.C., 1977: Diurnal variation in the occurrence of exceptional rainstorms. Weather, 32, 126-129.

Janowiak, J.E., P.A. Arkin and M. Morrissey, 1994: An examination of the diurnal cycle in oceanic tropical rainfall using satellite and in situ data. Mon. Wea. Rev., 122, 2296-2311.

Kato, K., J. Matsumoto and H. Iwasaki, 1995: Diurnal variation of $\mathrm{Cb}$-clusters over China and its relation to large-scale conditions in the summer of 1979. J. Meteor. Soc. Japan, 73, 1219-1234.

Kurihara, K. and T. Kato, 1997: Characteristics of diurnal variation of precipitation around Kyushu district during the baiu season. Tenki, 44, 631-636 (in Japanese).

Kuwagata, T., 1997: An analysis of summer rain showers over central Japan and its relation with the thermally induced circulation. J. Meteor. Soc. Japan, 75, 513527.

Laing, A.G. and J.M. Fritsch, 1993a: Mesoscale convective complexes over the Indian monsoon region. $J$. Climate, 6, 911-919.

Laing, A.G. and J.M. Fritsch, 1993b: Mesoscale convective complexes in Africa. Mon. Wea. Rev., 121, 2254-2263.

Maddox, R.A., 1980: Mesoscale convective complexes. Bull. Amer. Meteor. Soc., 61, 1374-1387.

McAnelly, R.L. and W.R. Cotton, 1989: The precipitation life cycle of mesoscale convective complexes over the central United States. Mon. Wea. Rev., 117, 784-808.

McCorcle, M.D., 1988: Simulation of surface-moisture effects on the Great Plains low-level jet. Mon. Wea. Rev., 116, 1705-1720.

Miller, R.A. and W.M. Frank, 1993: Radiative forcing of simulated tropical cloud clusters. Mon. Wea. Rev., 121, 482-498.

Misumi, Y., 1999: Diurnal variations of precipitation grouped into cloud categories around the Japanese archipelago in the warm season. J. Meteor. Soc. Japan, 77, 615-635.

Murakami, M., 1983: Analysis of the deep convective activity over the western Pacific and southeastern Asia. Part I: Diurnal variation. J. Meteor. Soc. Japan, 61, 60-76.

Muramatsu, T., 1983: Diurnal variations of satellitemeasured TBB areal distribution and eye diameter 
of mature typhoons. J. Meteor. Soc. Japan, 61, 7790.

Nicolini, M., K.M. Waldron and J. Paegle, 1993: Diurnal oscillations of low-level jets, vertical motion, and precipitation: A model case study. Mon. Wea. Rev., 121, 2588-2610.

Nitta, T. and S. Sekine, 1994: Diurnal variation of convective activity over the tropical western Pacific. $J$. Meteor. Soc. Japan, 72, 627-641.

Oki, T. and K. Musiake, 1994: Seasonal change of the diurnal cycle of precipitation over Japan and Malaysia. J. Appl. Meteor., 33, 1445-1463.

Okuta, M., 1970: Climatological study on heavy rainfalls in Japan. Pap. Meteor. Geophys., 21, 323-379 (in Japanese with English abstract).

Prasad, B., 1974: Diurnal variation of rainfall in Brahmaputra valley. Indian J. Meteor. Geophys., 25, 245-250.

Randall, D.A., Harshvardhan and D.A. Dazlich, 1991: Diurnal variability of the hydrological cycle in a general circulation model. J. Atmos. Sci., 48, 40-62.

Saitoh, T. and F. Kimura, 1998: Diurnal variation of convective precipitation in Chubu-Kanto area in the summer. Tenki, 45, 541-549 (in Japanese).

Sakawa, M., 1989: Principle and application of fuzzy theories. Morikita Shuppan, 185pp. (in Japanese)

Suzuki, E., 1992: Statistical techniques in meteorological analysis: Part I. Kisho Kenkyu Note No. 173, 1-34 (in Japanese).

Tagami, Y., 1990: Diurnal variation of precipitation frequency in the Japanese Islands. Geogr. Rev. Japan, 63A, 407-430 (in Japanese with English abstract).

Takeda, T. and H. Iwasaki, 1987: Some characteristics of meso-scale cloud clusters observed in east Asia between March and October 1980. J. Meteor. Soc. Japan, 65, 507-513.

Tatehira, R. and M. Hoshina, 1993: Regional variation in diurnal change of heavy rainfall. Tenki, 40, 325333 (in Japanese).

Tucker, D.F., 1993: Diurnal precipitation variations in south-central New Mexico. Mon. Wea. Rev., 121, 1979-1991.

Wallace, J.M., 1975: Diurnal variations of precipitation and thunderstorm frequency over the conterminous United States. Mon. Wea. Rev., 103, 406-419.

Winkler, J.A., B.R. Skeeter and P.D. Yamamoto, 1988: Seasonal variations in the diurnal characteristics of heavy hourly precipitation across the United States. Mon. Wea. Rev., 116, 1641-1658.

$\mathrm{Xu}, \mathrm{K} . \mathrm{M}$. and D.A. Randall, 1995: Impact of radiative transfer on the macroscopic behavior of cumulus ensembles. Part II: Mechanisms for cloud-radiation interactions. J. Atmos. Sci., 52, 800-817.

Yasuda, K., 1970: Climatological features of the heavy rainfall intensity (above $50 \mathrm{~mm} / \mathrm{hr}$ ) in Japan. Tenki, 17, 539-548 (in Japanese).

\title{
日本における強い降水の頻度の日变化
}

\author{
藤部文昭 \\ (気象研究所予報研究部)
}

18 年間のアメダス資料を使って日本における強い降水の頻度の日变化を調べた。降水の時間スケール を 3 種類に設定し $(1 、 3 、 6$ 時間降水)、それぞれ並の降水から極めて強い降水にわたるいくつかのしきい 值 $(5 \sim 80 \mathrm{~mm} / \mathrm{h} 、 10 \sim 160 \mathrm{~mm} / 3 \mathrm{~h} 、 20 \sim 320 \mathrm{~mm} / 6 \mathrm{~h})$ について日変化形を地点ごとに求めた後、そ れらの代表的パタンを fuzzy $c$-means method (FCM) を使って抽出することにより、日変化形の地域特性 を調べた。結果は次のように要約される。(a) 沿岸域とりわけ陸地の西側では朝に極大が現れる。(b) その 他の多くの地域, 特に山岳の南〜東側や内陸域の一部では夜半ごろに高頻度傾向が見られる。(c)一部の内 陸域とりわけ山岳地域の東側や隣接する平野では夕方に強い極大が現れる。(d) 南西諸島では昼間に極大 が見られる。これらのうち、夜半ごろの高頻度傾向は 1 時間降水量よりも 3 時間および 6 時間降水量のほ うが、また弱い降水よりも強い降水のほうが明瞭であり、「豪雨は夜に多い」という経験と合致する。 